WARM UP

\title{
Smelling salts
}

\section{P McCrory}

What's in a name? That which we call a rose

By any other name would smell as sweet

William Shakespeare (1564-1616)

Romeo and Juliet: act 2, scene 2

I was delving into some reference material recently, trying to track down details of early treatment of mild head injury, and I was struck by the repeated mention of smelling salts as a folk remedy for this problem. But just what are smelling salts? Do they work and can they cause injury?

Although smelling salts have recently undergone a resurgence of interest by athletes as a pre-game stimulant or as a "pick me up" when performance is flagging, it appears that little is really known or understood about these agents. Over time they have tended to remain a traditional part of the trainer's kit (along with the ubiquitous sponge and cold sprays) rather than in the medical bag.

In the setting of sporting head injury, there are still many individuals and organisations that recommend the use of smelling salts to try and revive the injured athlete. Most recent sports medicine textbooks, however, emphatically state that smelling salts are contraindicated as they cause a withdrawal reaction, with the potential to cause or exacerbate spine injury.

Take, for example, this early guideline for the management of unconscious patients from The treatment to restore natural breathing and circulation published in 1878 by Dr Peter Shepherd, Surgeon Major, Army Medical Department and an Associate of the Order of St John of Jerusalem. His approach was fairly dogmatic:

Rule 1 - "To Maintain a Free Entrance of Air into the Windpipe - Cleanse the mouth and nostrils; open the mouth; draw forward the patient's tongue, and keep it forward: an elastic band over the tongue and chin will answer the purpose. Remove all tight clothing from about the neck and chest."
Rule 2 - "To Adjust the Patient's Position - Place the patient on his back on a flat surface, inclined a little from the feet upwards; raise and support the head and shoulders on a small firm cushion or folded article of dress under the shoulder blades."

So far, so good, but now the approach gets a little beyond the usual on-field emergency management.

Rule 3 - "Should a warm bath be procurable, the body may be placed in it up to the neck. Raise the body for twenty seconds in a sitting position, dash cold water against the chest and face, and pass ammonia under the nose. The patient should not be kept in a warm bath for longer than five to six minutes." Rule 4 - "To Excite Inspiration During the employment of the above method excite the nostrils with snuff or smelling salts, tickle the throat with a feather. Rub the chest and face briskly, and dash cold and hot water alternately on them."

Rule 5 - "To Induce Circulation and Warmth - Wrap the patient in dry blankets and commence rubbing the limbs upwards firmly and energetically. The friction must be continued under the blankets or over the dry clothing. Promote the warmth of the body by the application of hot flannels, bottles or bladders of hot water, heated bricks etc., to the armpits, the pit of the stomach, between the thighs and the soles of the feet. On the restoration of life, when the power of swallowing has returned, a teaspoon of warm water, small quantities of wine, warm brandy and water, or coffee should be given. The patient should be kept in bed and a disposition to sleep encouraged. During reaction, large mustard plasters to the chest and below the shoulders will greatly relieve the distressed breathing."

So one can see the team doctor of the Victorian era armed with his smelling salts, feather, hot flannels, heated bricks, brandy, coffee and mustard poultices (presumably with a team Sherpas to carry them all) performing a valuable service to sports teams. Our current team physician training does seem to lack a certain cachet when compared with those of our medical ancestors.

WHAT ARE SMELLING SALTS?

By definition, they are any of preparations of ammonium carbonate $\left(\left(\mathrm{NH}_{4}\right)_{2} \mathrm{CO}_{3} \mathrm{H}_{2} \mathrm{O}\right)$ and perfume, sniffed as a restorative or stimulant. Traditionally, they were sniffed as a stimulant to relieve faintness or swooning. Smelling salts may also simply be dilute ammonia dissolved in a mixture of water and ethanol and most forms of "smelling salts" available on the internet are this latter type of mixture. These mixtures should be more correctly termed "aromatic spirits of ammonia."

It may be of interest to some that there is a surprisingly long history of the use of such agents. The term Hammoniacus sal appears in the writings of Pliny, although it is not known whether the term is identical to the more modern sal ammoniac, which was known to the alchemists as early as the $13^{\text {th }}$ century. Chaucer also noted the existence of sal ammoniac alongside a large number of other materia medica. This spirit was mainly used by textile dyers in the Middle Ages in the form of fermented urine to alter the colour of vegetable dyes.

In the $17^{\text {th }}$ century an aqueous solution of ammonia (also called aquila coelestis) was obtained from the distillation of shavings of harts' horns and hooves. When crystallised, this chemical turned out to be ammonium carbonate and was initially called salt (or spirit) of hartshorn and later became known as smelling salts when mixed with perfumes. It is also known as "baker's ammonia" and was a forerunner to the more modern leavening agents such as baking soda and baking powder.

\section{HOW DO SMELLING SALTS WORK?}

Smelling salts are used to arouse consciousness because the release of ammonia $\left(\mathrm{NH}_{3}\right)$ gas that accompanies their use irritates the membranes of the nose and lungs, and thereby triggers an inhalation reflex. This reflex alters the pattern of breathing, resulting in improved respiratory flow rates and possibly alertness.

Are smelling salts likely to work for sport-related mild head injury? It is unlikely that the induced inhalational reflex has a significant therapeutic effect over and above the natural history 
of the condition. Increasing the respiratory rate alone certainly has no beneficial pathophysiological effect on the nature or underlying cause of concussive injury. Whether the salts increase alertness or improve reaction times or have other positive cognitive benefits remains to be proven scientifically.

\section{DO SMELLING SALTS CAUSE INJURY?}

While there are numerous case reports of the toxicity of ammoniacal agents when ingested in large doses or inhaled in high concentration for prolonged periods there are, in fact, no reports of adverse health problems related to the use of smelling salts in sport.

The product information for commercially available smelling salts clearly recommends that the capsule or solution be held $10-15 \mathrm{~cm}$ away from the patient's nose. This, I suspect, is designed to limit any direct burning effect on the nasal or oral mucosa from high concentrations of the inhaled ammonia. This risk is not a new one and as Charles Dickens so eloquently put it in Hard Times (chapter 16) "...on his way home...he took the precaution of stepping into a chemist's shop and buying a bottle of the very strongest smelling-salts. 'By George!' said Mr. Bounderby, 'if she takes it in the fainting way, I'll have the skin off her nose, at all events!".

With regard to sporting concussions, the real danger is that reaching for smelling salts in this situation is not a substitute for a careful and complete neurological assessment. More serious head injuries may often masquerade in the early stages as a minor head injury and inexperienced carers may falsely assume that an initial improvement, thought to be due to the beneficial effects of smelling salts, may well mask the development of more sinister complications.

It is important to note that it is an inhalation reflex, not a neck movement, that is induced by smelling salts, which simply results in increased rate and depth of breathing. It is possible that holding the salts too close to the nose $(<10 \mathrm{~cm})$ may cause a neck movement simply as an irritant. This reflects the incorrect application of the salts, however, rather than a negative effect of the agent itself.

\section{CONCLUSION}

In Victorian historical tradition, smelling salts were an effective method of helping ladies who had fallen prey to fainting fits. In modern sports medicine, however, when used correctly, smelling salts are unlikely to have significant benefit or cause significant adverse effects in sport-related head injury. The real danger is that the injudicious use of these agents as a substitute for a medical assessment may delay optimal treatment and, as such, should not be recommended.

Br J Sports Med 2006;40:659-660.

doi: $10.1136 / \mathrm{bjsm} .2006 .029710$ 


\section{Expression of concern about content of which Dr Paul McCrory is a single author}

This paper is authored by Dr Paul McCrory. During 2021 and 2022 there was an investigation by BJSM and BMJ which found that some of his work was the product of publication misconduct. Such misconduct includes plagiarism, duplicate publication, misquotation and misrepresentation in publications in respect of which he was listed as the sole author. ${ }^{1}$ We are placing a notice to readers on all content in relation to which he is identified as the sole author to alert them to the conclusions of our investigation.

(C) Author(s) (or their employer(s)) 2022. No commercial re-use. See rights and permissions. Published by BMJ.

Br J Sports Med 2022;0:1. doi:10.1136/bjsports-2022-106408eoc

D) Check for updates

\section{REFERENCE}

1 Macdonald H, Ragavooloo S, Abbasi K. Update into the investigation of former BJSM editor-in-chief Paul McCrory. Br I Sports Med 2022. 